\title{
A formação do mercado de trabalho acadêmico no Brasil (1990-2009)
}

\author{
Manoel Santana Cardoso \\ Orientador: Doutora Ana Maria Fernandes \\ Tese de Doutorado \\ Data da defesa: 15.12.2012
}

presente tese tem como temática a consolidação e expansão de um
mercado de trabalho acadêmico no Brasil e suas relações com outras
esferas no âmbito da sociedade brasileira. O trabalho parte da institucionalização da pós-graduação no Brasil e suas inter-relações com outras políticas públicas, mais especificamente o ensino superior, a partir dos anos 50 do século passado até os dias atuais. O objeto de análise foi circunscrito primeiramente ao ambiente acadêmico, aqui entendido como universidades e centros de pesquisa. Em um segundo momento, também a burocracia pública e empresas de base tecnológica foram palco da investigação, considerando que, nos dias atuais, as mesmas representam francas opções para profissionais de todas as áreas do conhecimento que sejam detentores de um título de mestre ou doutor. Assim, foram examinados, entre outros, os Planos Nacionais de Pós-graduação, documentos síntese da política praticada pela Coordenação de Aperfeiçoamento de Pessoal de Nível Superior-Capes. O principal objetivo foi estabelecer quais mecanismos atuaram sobre o mercado de trabalho acadêmico brasileiro, determinando sua constituição e expansão ao longo de um período circunscrito, 1990 a 2009, bem como as relações com outros fenômenos sociais que lhe são correlatos. Ao final da pesquisa, concluiu-se que o mercado de trabalho acadêmico no Brasil foi-se constituindo, ao longo do período analisado, por meio de uma estreita associação entre a comunidade científica brasileira e o estado, a partir de sua inserção nas agências de fomento à pós-graduação e à pesquisa, notadamente a Fundação Capes.

Palavras-chave: Pós-Graduação, Ensino Superior, Mercado de Trabalho, Doutores, Educação, Políticas públicas. 